\title{
SEISMIC CODE ANALYSIS OF MULTI-STOREY ASYMMETRIC BUILDINGS
}

\author{
ANTHONY P. HARASIMOWICZ ${ }^{1 \dagger}$ AND RAKESH K. GOEL ${ }^{2 * \ddagger}$ \\ ${ }^{1}$ Department of Civil and Environmental Engineering, Syracuse University, Syracuse, NY 13244-1190, U.S.A. \\ ${ }^{2}$ Department of Civil and Environmental Engineering, Cal Poly State University, San Luis Obispo, CA 93407, U.S.A.
}

\begin{abstract}
SUMMARY
Static torsional provisions in most seismic codes require that the lateral force at each floor level be applied at some distance from the reference centre at that floor. However, codes do not specify how to determine the locations of these centres. As a result, several different definitions of the reference centres are being used to implement the code analysis. This investigation examined how the results using various reference centres differ and which of these centres would lead to results that are in agreement with those of dynamic analysis. For this purpose three different buildings ranging form torsionally stiff to torsionally flexible were analysed. It was shown that for the class of buildings studied in this investigation that although the locations of the reference centres were quite different, the results were very similar and nearly independent of the reference centre. Comparison of results calculated from static code equivalent lateral force procedures and results from dynamic response spectrum analyses showed that the static code procedures led to design forces very close (flexible wall) or slightly conservative (stiff wall) when compared to the dynamic analysis for the torsionally stiff building. However, the static code procedures significantly underestimated the design forces of the stiff walls and significantly overestimated the design forces of the flexible walls for the torsionally flexible buildings. (C) 1998 John Wiley \& Sons, Ltd.
\end{abstract}

Earthquake Engng. Struct. Dyn., 27, 173-185 (1998)

KEY WORDS: asymmetric buildings; building codes; earthquake analysis; plan asymmetry; seismic codes; torsion

\section{INTRODUCTION}

Most seismic codes permit two alternative procedures for estimating distribution of forces in buildings: the static procedure, which applies primarily to regular buildings, and the dynamic procedure, which applies especially to buildings with significant irregularities either in plan or elevation.

The static procedures, in most building codes, ${ }^{1}$ require that the design base shear be computed from

$$
V_{b}=C_{s} W
$$

where $W$ is the total seismic dead load, consisting of the total dead load and applicable portions of other loads, and $C_{\mathrm{s}}$ is the seismic coefficient which depends on factors such as the fundamental vibration period of the building, expected seismic activity at the building site, building importance, soil type and capacity of the building to safely undergo inelastic deformation.

The distribution of lateral forces over the height of the building is then determined from the base shear in accordance with a specified formula for the lateral force at the $j$ th floor. For example, the formula specified in

\footnotetext{
* Correspondence to: R. K. Goel, Department of Civil and Environmental Engineering, Cal Poly State University, Room 263, Building 13, San Luis Obispo, CA 93407, U.S.A. E-mail: rgoel@calpoly.edu

+ Graduate student

* Assistant Professor. Previously at Syracuse University
} 
NBCC- $95^{2}$ is of the form

$$
F_{j}=\left(V_{b}-F_{t}\right) \frac{w_{j} h_{j}}{\sum_{i=1}^{N} w_{i} h_{i}}
$$

with the exception that the force at the top-floor level computed from Equation (1b) is increased by an additional force according to

$$
F_{t}= \begin{cases}0, & T<0 \cdot 7 \\ 0.07 T V_{b}, & 0 \cdot 7 \leqslant T \leqslant 3 \cdot 6 \\ 0.25 V_{b}, & T \geqslant 3.6\end{cases}
$$

In equations (1b) and (1c), $F_{j}$ is the lateral force applied to level $h_{j}, h_{j}$ the height above the base to level $j$, $w_{j}$ the seismic dead weight at level $j$ and $T$ the fundamental vibration period. Additional details of the above-described procedure are available in a recently published book by Chopra. ${ }^{3}$

For asymmetric-plan buildings, the lateral force at each floor level is applied at a distance equal to the design eccentricity, from a reference centre, at that floor. ${ }^{1}$ The design eccentricity, $e_{d j}$, at level $j$, is usually defined as

$$
\begin{aligned}
& e_{d j}=\alpha e_{s j}+\beta b_{j} \\
& e_{d j}=\delta e_{s j}-\beta b_{j}
\end{aligned}
$$

in which $e_{s j}$ is the static or 'structural eccentricity' at level $j, b_{j}$ the floor plan dimension of the building perpendicular to the direction of ground motion and $\alpha, \beta$, and $\delta$ are the specified coefficients. For example, $\alpha=1 \cdot 5, \delta=0 \cdot 5$, and $\beta=0 \cdot 1$ in the NBCC-95. ${ }^{2}$

The structural eccentricity in equations ( $2 a)$ and ( $2 b)$ accounts for the coupled lateral-torsional effect due to the lack of symmetry in plan and is defined as the distance between the floor Centre of Mass (CM) and the reference centre. The $\beta b_{j}$ term is often referred to as the 'accidental eccentricity' and is specified as a fraction of the plan dimension, $b_{j}$. This accidental portion accounts for such effects as differences between computed and actual values of stiffness, yield strengths, dead-load masses and unforeseeable detrimental live-load distributions.

The dynamic analysis procedures specified in seismic codes utilize one of the two well-established procedures for linear dynamic analysis: the response spectrum analysis and the time-history analysis. The response spectrum analysis may utilize the code-specific design spectrum or the site-specific spectrum. The time history analysis may use ground motion histories from past earthquakes at the same site (or similar site), or artificially developed acceleration histories to be compatible with the motions expected at the building site. Some seismic codes, for example NBCC-95, also permit non-linear analysis.

One of the major obstacles to implementing the static procedure for multi-storey, asymmetric-plan buildings is that there is no unanimously accepted definition or name for the reference centres. ${ }^{4-7}$ Poole $^{4}$ defined the reference centre, denoted as the centre of rigidity, of a story as the location of the resultant of shear forces of various resisting elements in that storey when the building is subjected to a static lateral loading that causes no rotation in any of the stories. Humar ${ }^{5}$ defined the reference centre, denoted as centre of resistance, at any floor to be the point such that the application of a lateral load through this point would not cause rotation of that floor, however other floors are allowed to rotate. Cheung and Tso ${ }^{6}$ and Hejal and Chopra ${ }^{7}$ defined the reference centres, denoted as centres of rigidity, as the set of points located on the building floors through which the application of lateral forces would cause no rotation of any of the floors. Further clarification on various reference centres has been provided by Hejal and $\mathrm{Chopra}^{7}$ and Jiang et al. $^{8}$

Additional names used for the reference centre are the centre of twist and shear centre; details are available in a report by Hejal and Chopra. ${ }^{7}$ The centres of twist of the floors of a building are defined as the points on 
the floor diaphragms which remain stationary when the building is subjected to any set of static horizontal torsional moments, applied at the floor levels, i.e. the floor diaphragms undergo pure twist about these points. The shear centre of a floor of the building is the point on the floors through which the resultant of the interstorey shear forces at the level (due to static forces applied at the floors above and including the floor in consideration) experienced by all resisting elements passes when the floors of the building are subjected to static horizontal forces that cause no twist in any of the floors.

Unlike one-storey buildings, locations of the above-mentioned reference centres for a multistorey building may not be identical unless it belongs to a special class known as proportional buildings. ${ }^{6,7,9,10}$ Their locations not only depend on the geometric and stiffness characteristics of the building, but also on the applied loading. Therefore, there is a need to determine which of these reference centres is the most appropriate choice for implementing the static torsional provisions of seismic codes.

With the aim of filling this need, this investigation examined how the results using various reference centres differ and which of these centres would lead to results that are in agreement with those of dynamic analysis. Results for shear centre as the reference centre are not included because it has been demonstrated by Tso ${ }^{11}$ that the floor forces applied at the CRs and the storey shears applied at the shear centres lead to identical member forces. It should be noted that code static provisions also account for inelastic behaviour of buildings under seismic loading. However, the scope of this paper is limited to linear elastic range of behaviour; several other investigations have examined the inelastic behaviour.

\section{SYSTEM CONSIDERED}

The general system considered is a nine-storey building with uniform rectangular floors of dimensions, $20 \mathrm{~m} \times 10 \mathrm{~m}$ (Figure 1) and a uniform floor height of $3 \mathrm{~m}$ (adopted from Cheung and Tso ${ }^{6}$ ). The building has six wall elements to resist lateral loads and the arrangement of these elements is symmetric in the $X$-direction and eccentric in the $Y$-direction. The stiffnesses at the top three floors of all elements, except wall 4, are reduced to two-thirds that at the base. Therefore, this building represents a building where framing is non-proportional. Other information concerning the building is summarized in Table I.

Three different building configurations were analysed in this investigation. For each of the three building cases, they all possessed the same floor dimensions, floor height and number of floors. Each building also contained the same wall elements as given in Table I. Case 1 has wall elements 1, 4, 5 and 6 at the edges of the building plan and wall elements 2 and 3 at a distance of $3 \mathrm{~m}$ on either side of the CM in the $X$-direction. Building cases 2 and 3 have just a rearrangement of the wall elements. Case 3 , in particular, has wall elements 2, 3, 5 and 6 located at the CM. As will be demonstrated latter in the paper, case 1 represents a torsionallystiff building and case 3 corresponds to a torsionally flexible building; case 2 represents a building between these two extremes. For each building case, wall 1 is designated as the stiff wall as this wall possessed the largest stiffness (Table I). The outermost wall on the opposite building side, i.e., wall 4 , is denoted as the flexible wall.

\section{METHOD OF ANALYSIS}

The selected buildings were assumed to be located in the most seismic zone in Canada and subjected to lateral loading in the $Y$-direction. The shear forces and bending moments in the various resisting elements were computed based on two approaches. The first approach utilized the equivalent static lateral load analysis of the National Building Code of Canada, 1995 (NBCC-95). ${ }^{2}$ The second approach used a dynamic modal response spectrum analysis with complete quadratic combination (CQC) of modal responses. The following sections describe how these approaches were implemented for analysis of the selected building cases. 

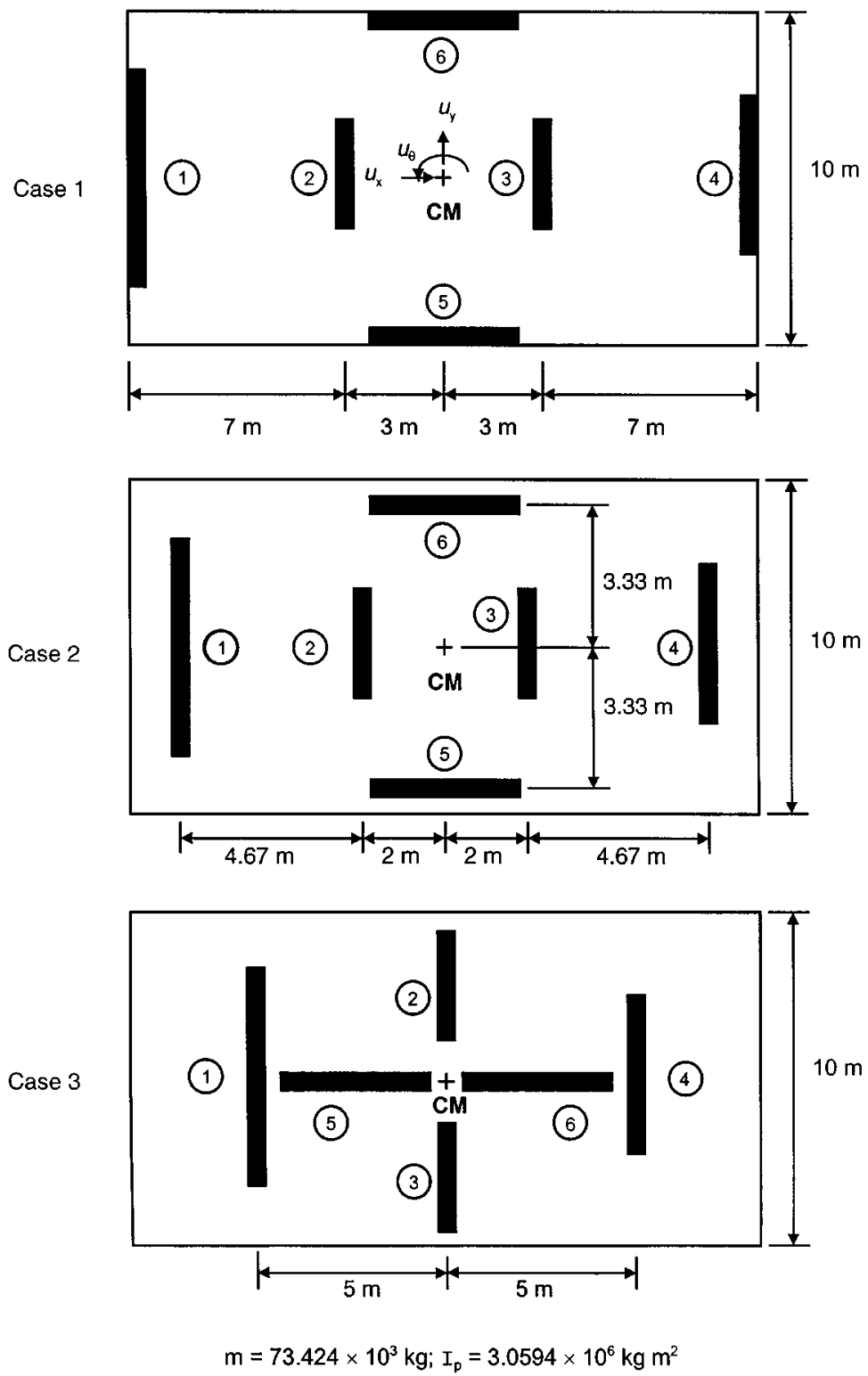

Figure 1. Framing plan of the selected buildings (adapted from Cheung and Tso ${ }^{6}$ )

\section{Static code analysis}

Equivalent lateral forces. The calculation of equivalent lateral forces involved two steps. The first step was the calculation of the base shear which among other factors, depends on the fundamental period of the building. The fundamental period, calculated based on the empirical formula given in NBCC-95, for each building case was $0.768 \mathrm{~s}$ (because $h_{n}$ and $D_{s}$ remained the same for each building case). This period led to a corresponding value for the seismic response factor of $1 \cdot 72$. This building was designed for a zonal velocity ratio of $0 \cdot 4$, a seismic importance factor of 1 , a foundation factor of 1 , a calibration factor of $0 \cdot 6$, and a force modification factor of $3 \cdot 5$. The calculated base shear was then used to determine the distribution of lateral 
Table I. Flexural rigidities of resisting elements

\begin{tabular}{cccccccc}
\hline & \multicolumn{7}{c}{ Elements } \\
Building & Floor & 1 & 2 & 3 & 4 & 5 & 6 \\
\hline 1 & $7-9$ & 12 EI & 2EI & 2EI & 6 EI & 5 EI & 5 EI \\
& $1-6$ & 18 EI & $3 E I$ & $3 E I$ & 6 EI & $7 \cdot 5 \mathrm{EI}$ & $7 \cdot 5 \mathrm{EI}$ \\
\hline
\end{tabular}

Note: $\mathrm{EI}=6.4 \times 10^{9} \mathrm{~N} \mathrm{~m}^{2}$

Table II. Static code lateral force distribution

\begin{tabular}{ccccccc}
\hline Floor & $\begin{array}{c}V \\
(\mathrm{kN})\end{array}$ & $\begin{array}{c}F_{\mathrm{t}} \\
(\mathrm{kN})\end{array}$ & $\begin{array}{c}h_{j} \\
(\mathrm{~m})\end{array}$ & $\begin{array}{c}w_{j} h_{j} \\
(\mathrm{kN} \mathrm{m})\end{array}$ & $\begin{array}{c}w_{i} h_{i} \\
(\mathrm{kN} \mathrm{m})\end{array}$ & $\begin{array}{c}F_{j} \\
(\mathrm{kN})\end{array}$ \\
\hline 1 & 761 & $40 \cdot 9$ & 3 & 220 & 9912 & 16 \\
2 & 761 & $40 \cdot 9$ & 6 & 441 & 9912 & 32 \\
3 & 761 & $40 \cdot 9$ & 9 & 661 & 9912 & 48 \\
4 & 761 & $40 \cdot 9$ & 12 & 881 & 9912 & 64 \\
5 & 761 & $40 \cdot 9$ & 15 & 1101 & 9912 & 80 \\
6 & 761 & $40 \cdot 9$ & 18 & 1321 & 9912 & 96 \\
7 & 761 & $40 \cdot 9$ & 21 & 1542 & 9912 & 111 \\
8 & 761 & $40 \cdot 9$ & 24 & 1762 & 9912 & 127 \\
9 & 761 & $40 \cdot 9$ & 27 & 1982 & 9912 & 184 \\
\hline
\end{tabular}

forces over the building height in accordance with the NBCC-95 formula for the height wise distribution of the lateral forces. The resulting height-wise distribution of forces is presented in Table II; details are available in Reference 12, Appendix 1.

Locations of reference centers. Required in implementing the static code procedure for asymmetric plan buildings were the locations of the reference centres. Since codes do not explicitly specify how to determine these locations, the following reference centres were utilized in the investigation: (1) the centre of rigidity $(\mathrm{CR})$ defined by Cheung and Tso ${ }^{6}$ and Hejal and Chopra; ${ }^{7}$ (2) the centre of resistance, defined by Humar ${ }^{5}$ and (3) the Centre of Twist (CT) defined by Hejal and Chopra. ${ }^{7}$ It can be easily shown (details available in Reference 12, Appendix 2) that the centre of resistance at a floor level defined by Humar ${ }^{5}$ is the same as the centre of twist at that level computed by applying a static torsional moment at that floor level only (static torsional moments at other floor levels are zero). Therefore, the centre of resistance is denoted as Single-floor Center of Twist (SCT) in this paper.

It is important to note that the CRs and CTs/SCTs were load-dependent for the selected buildings because these buildings did not belong to the special class. For each building, the locations of the CRs were calculated by utilizing the height-wise lateral force distribution of Table II. The locations of the CTs were computed based on equal torsional moments at all floors. Other distributions of torsional moments were also used for calculating the CTs. However, for the buildings under consideration, CTs were essentially independent of the torsional moment distribution. Additional details on how to calculate these reference centers are presented in Reference 12, Appendix 2.

The locations of the CRs, CTs, and SCTs are shown in Figure 2 for each building and numerical values are given in Table III. The CRs were found on both sides of the CM, and for case 1, floors six and seven had CRs 
Case 1

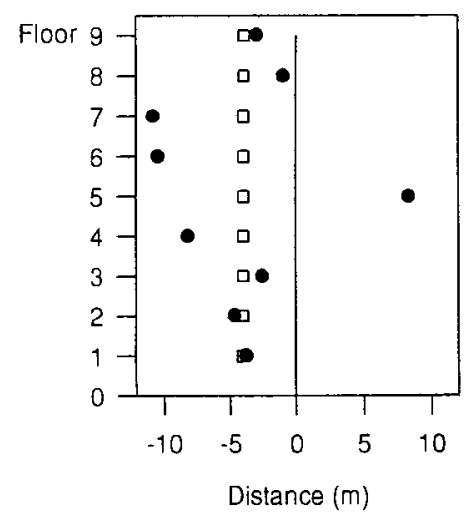

(a)

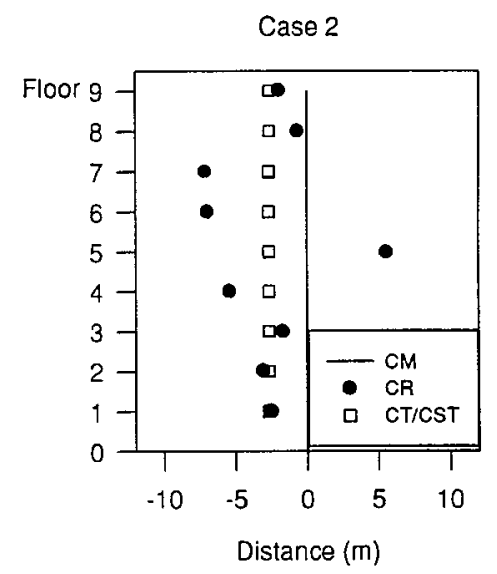

(b)

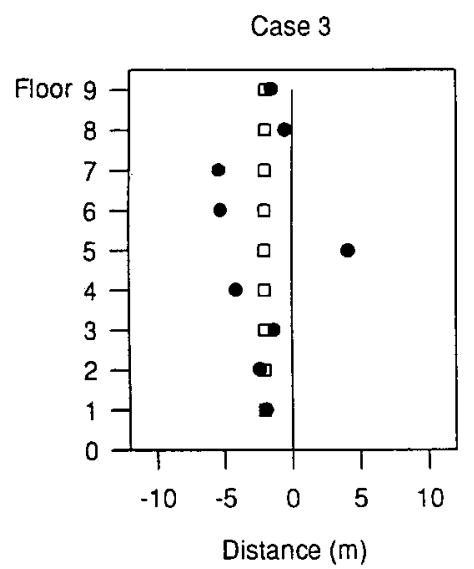

(c)

Figure 2. Locations of centres of rigidity and twist

Table III. Numerical values of centres of rigidity and twist

\begin{tabular}{|c|c|c|c|c|c|c|c|c|c|}
\hline \multirow[b]{2}{*}{ Floor } & \multicolumn{3}{|c|}{ Case 1} & \multicolumn{3}{|c|}{ Case 2} & \multicolumn{3}{|c|}{ Case 3} \\
\hline & $\begin{array}{l}\text { CR } \\
(\mathrm{m})\end{array}$ & $\begin{array}{l}\text { CT } \\
(\mathrm{m})\end{array}$ & $\begin{array}{c}\text { CST } \\
(\mathrm{m})\end{array}$ & $\begin{array}{l}\text { CR } \\
(\mathrm{m})\end{array}$ & $\begin{array}{l}\text { CT } \\
(\mathrm{m})\end{array}$ & $\begin{array}{c}\text { CST } \\
(\mathrm{m})\end{array}$ & $\begin{array}{l}\text { CR } \\
(\mathrm{m})\end{array}$ & $\begin{array}{l}\text { CT } \\
(\mathrm{m})\end{array}$ & $\begin{array}{c}\text { CST } \\
(\mathrm{m})\end{array}$ \\
\hline 9 & $-2 \cdot 93$ & -3.98 & -3.94 & -1.95 & -2.65 & -2.63 & -1.46 & -1.99 & -1.97 \\
\hline 8 & -0.98 & -3.99 & -3.98 & -0.65 & $-2 \cdot 66$ & $-2 \cdot 65$ & $-0 \cdot 49$ & -1.99 & -1.99 \\
\hline 7 & $-10 \cdot 71$ & -3.99 & $-4 \cdot 00$ & $-7 \cdot 15$ & -2.66 & -2.67 & $-5 \cdot 36$ & $-2 \cdot 00$ & $-2 \cdot 00$ \\
\hline 6 & $-10 \cdot 39$ & $-4 \cdot 00$ & $-4 \cdot 00$ & -6.93 & -2.67 & $-2 \cdot 67$ & $-5 \cdot 19$ & $-2 \cdot 00$ & $-2 \cdot 00$ \\
\hline 5 & $8 \cdot 37$ & $-4 \cdot 00$ & $-4 \cdot 00$ & $5 \cdot 58$ & -2.67 & -2.67 & $4 \cdot 18$ & $-2 \cdot 00$ & $-2 \cdot 00$ \\
\hline 4 & $-8 \cdot 14$ & $-4 \cdot 00$ & $-4 \cdot 00$ & $-5 \cdot 43$ & $-2 \cdot 67$ & -2.67 & $-4 \cdot 07$ & $-2 \cdot 00$ & $-2 \cdot 00$ \\
\hline 3 & $-2 \cdot 52$ & $-4 \cdot 00$ & $-4 \cdot 00$ & -1.68 & -2.67 & -2.67 & $-1 \cdot 26$ & $-2 \cdot 00$ & $-2 \cdot 00$ \\
\hline 2 & $-4 \cdot 60$ & $-4 \cdot 00$ & $-4 \cdot 00$ & -3.07 & $-2 \cdot 67$ & -2.67 & $-2 \cdot 30$ & $-2 \cdot 00$ & $-2 \cdot 00$ \\
\hline 1 & -3.66 & $-4 \cdot 00$ & $-4 \cdot 00$ & $-2 \cdot 44$ & -2.67 & -2.67 & $-1 \cdot 83$ & $-2 \cdot 00$ & $-2 \cdot 00$ \\
\hline
\end{tabular}

that did not even lie on the building plan. Given that the design eccentricity is defined as the distance between the $\mathrm{CR}$ and the CM, the design eccentricity would assume both positive and negative values along the building height. The CTs and SCTs are essentially identical and their variation over each building's height was negligible as all values were approximately equal (Table III). As a result, the design eccentricities took on nearly equivalent values for all floors. The CRs and CTs (or SCTs) exhibited very different patterns for the selected buildings; the CRs were generally scattered values and the CTs (or SCTs) were generally constant values. The above trends were apparent for each building case, and the patterns were very similar. Cases 2 and 3 (Figures. 2(b) and 2(c)) have the same general distribution of CRs, CTs, and SCTs, but with values located closer to the CM.

\section{Dynamic response spectrum analysis}

Mode shapes and frequencies. Mode shapes and frequencies were computed for each case corresponding to $Y$ and $\theta$ degrees of freedom as the considered systems were coupled in $Y$ and $\theta$ motions; systems are symmetric in the $X$-direction and hence no coupling would occur between $X$ and $\theta$ motions. The computed 
Case 1

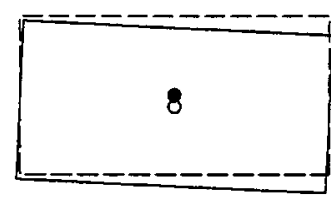

$T_{1}=0.599 \mathrm{sec}$

(a)

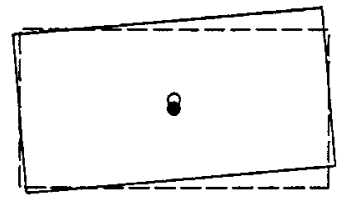

$\mathrm{T}_{1}=0.674 \mathrm{sec}$

(c)

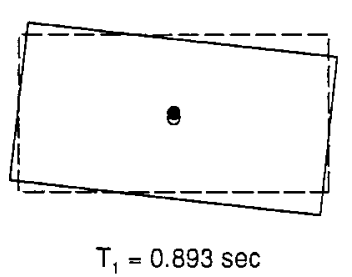

(e)

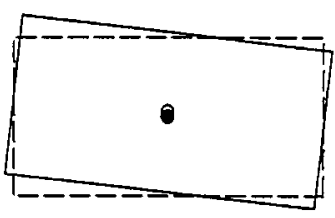

$\mathrm{T}_{2}=0.327 \mathrm{sec}$

(b)

Case 2

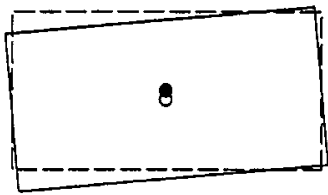

$T_{2}=0.436 \mathrm{sec}$

(d)

Case 3

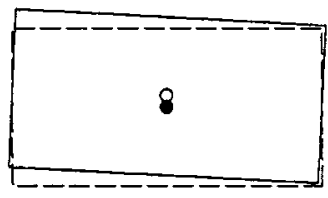

$T_{2}=0.484 \mathrm{sec}$

(f)

$$
\begin{array}{ll}
-- \text { undeflected roof plan } \\
- \text { deflected roof plan } \\
\text { - undeflected CM } \\
\text { deflected CM }
\end{array}
$$

Figure 3. Translational and rotational displacements at roof level, cases 1-3

frequencies, periods and modal participation factors (due to excitation in the $Y$-direction only) for the first six modes (out of a total of 18) are presented in Table IV.

The first two mode shapes (at the roof level) for each of the three building cases are plotted in Figure 3. These results reveal several important dynamic characteristics of the systems considered in this study. Building case 1 corresponds to a torsionally stiff structure as the first mode is primarily translational (Fig. 3a)), as apparent by significant translation displacement of the CM, and the second mode is primarily torsional (Figure 3(b)), as given by the very little translation but large rotation of the CM. Furthermore, the modal participation factor for the first mode is significantly larger as compared to the second mode (Table IV). Conversely, building case 3 corresponds to a torsionally flexible structure as the first mode is primarily torsional (Figure 3e) and the second mode is primarily transitional (Figure 3f). The participation factors again display this trend as the second mode participation factor is much larger than that of the first mode (Table IV). Building case 2 reveals a medium between the torsionally stiff structure of case 1 and the torsionally flexible structure of case 3 as both modes display significant coupling between translational and 
Table IV. Circular frequencies, periods, and participation factors for contributing modes

\begin{tabular}{|c|c|c|c|c|c|c|c|c|c|}
\hline \multirow[b]{2}{*}{ Mode } & \multicolumn{3}{|c|}{ Case 1} & \multicolumn{3}{|c|}{ Case 2} & \multicolumn{3}{|c|}{ Case 3} \\
\hline & $\begin{array}{c}\omega \\
(\mathrm{rad} / \mathrm{s})\end{array}$ & $\begin{array}{c}T \\
(\mathrm{sec})\end{array}$ & $\Gamma_{n}$ & $\begin{array}{c}\omega \\
(\mathrm{rad} / \mathrm{s})\end{array}$ & $\begin{array}{c}T \\
(\mathrm{sec})\end{array}$ & $\Gamma_{n}$ & $\begin{array}{c}\omega \\
(\mathrm{rad} / \mathrm{s})\end{array}$ & $\begin{array}{c}T \\
(\mathrm{sec})\end{array}$ & $\Gamma_{n}$ \\
\hline 1 & $10 \cdot 49$ & 0.599 & $-605 \cdot 92$ & $9 \cdot 33$ & 0.674 & $464 \cdot 55$ & $7 \cdot 04$ & 0.893 & -276.06 \\
\hline 2 & $19 \cdot 23$ & $0 \cdot 327$ & $246 \cdot 07$ & $14 \cdot 42$ & $0 \cdot 436$ & $-460 \cdot 32$ & $12 \cdot 97$ & $0 \cdot 484$ & $592 \cdot 90$ \\
\hline 3 & $65 \cdot 29$ & 0.096 & $-335 \cdot 75$ & $58 \cdot 28$ & $0 \cdot 108$ & $-256 \cdot 34$ & $44 \cdot 01$ & $0 \cdot 143$ & $147 \cdot 37$ \\
\hline 4 & $116 \cdot 92$ & $0 \cdot 054$ & $-123 \cdot 17$ & $87 \cdot 37$ & 0.072 & $-250 \cdot 31$ & $78 \cdot 74$ & $0 \cdot 080$ & $327 \cdot 31$ \\
\hline 5 & $180 \cdot 75$ & 0.035 & $204 \cdot 62$ & $162 \cdot 07$ & 0.039 & -151.95 & $122 \cdot 59$ & $0 \cdot 051$ & -75.06 \\
\hline 6 & $315 \cdot 72$ & 0.022 & $-57 \cdot 69$ & $235 \cdot 1$ & 0.027 & $152 \cdot 67$ & $212 \cdot 34$ & $0 \cdot 030$ & $-204 \cdot 46$ \\
\hline
\end{tabular}

rotational motions (Figures 3(c) and 3(d)) and the first and second mode participation factors are nearly identical (Table IV) representing nearly equivalent translational and rotational components.

As given by the results presented in Table IV, the fundamental period of building from the dynamic analysis was calculated to be $0.599 \mathrm{sec}$ for case 1 . This period was about 20 per cent shorter that the period of $0.768 \mathrm{sec}$ computed from the NBCC-95 empirical formula. This observation contradicts the generally expected trend, that the fundamental period of a building from the empirical formula would be shorter than its actual period, or period from the dynamic analysis. The fundamental periods from dynamic analysis for cases 2 and 3 were 0.674 and 0.893 sec, respectively. Since longer periods from the empirical formulas (cases 1 and 2) may lead to underestimation of design forces, this issue should be further examined and code empirical formulas revised. A recent study by Goel and Chopra ${ }^{13}$ also raised such a concern for empirical period formulas in U.S. building codes for shear wall buildings.

Response spectrum analysis. The NBCC-95 requires that enough modes should be included to capture at least 90 per cent of the total building mass. For each building case, the first six modes satisfied this criteria. The frequencies and periods of these modes are presented in Table IV. This table also gives values for the participation factor, $\Gamma_{n}$ ( $n$ is the mode number), for each contributing mode. With the given quantities in Table IV, and the corresponding mode shape $\phi_{n}$, the member forces for each contributing mode, due to dynamic loading, were computed for each member and the modal responses were combined using CQC method. The following design spectrum was utilized in the response spectrum analysis (NBCC-95 User's Guide: Part $4^{14}$ ):

$$
\frac{A}{g}= \begin{cases}1 \cdot 2, & T_{n} \leqslant 0.427 \\ 0.512 / T_{n}, & T_{n}>0.427\end{cases}
$$

Consideration of accidental eccentricity. The effect of accidental eccentricity may be included in the dynamic analysis by two approaches. ${ }^{15,16}$ The first approach involves shifting the CMs from their original locations, at each floor level, by a distance equal to the accidental eccentricity, and then implementing the dynamic analysis. The second approach involves the superposition of results due to the application of static torsional moments, at each floor level equal to the lateral force times the accidental eccentricity at that floor, to the results from the dynamic analysis of the building without shifting the CMs from their original locations. It has been shown that the two approaches may lead to significantly different results. ${ }^{16}$ However, the second approach was adopted in this investigation because this approach is the one specified in NBCC-95 (User's Guide: Part 4 [NBC-95 4.1.9.1.(13)(b) Clause 44g] ${ }^{14}$ ). The value of the accidental eccentricity at each floor level was considered equal to: $0 \cdot 1 b=0 \cdot 1(20 \mathrm{~m})=2 \mathrm{~m}$. 
Normalization of results. The NBCC-95 stipulates that results from the dynamic analysis should be scaled by a factor equal to $V / V_{\text {dyn }}$, in which $V$ is the base shear from the static analysis and $V_{\text {dyn }}$ is the base shear from the dynamic analysis (User's Guide: Part 4 [NBC-95 4.1.9.1.(13)(b) Clause 44e $]^{14}$ ). The first step in this normalization process involved the results after performing the CQC analysis which yielded values corresponding to the $V_{e}$ term in the expression; $V=\left(V_{e} / R\right) \times U$, where $V_{e}$ is the elastic level seismic lateral force (Reference 12, Appendix 1). Therefore, to obtain values corresponding to $V$, the dynamic results had to be multiplied by a factor of $(U / R)=(0 \cdot 6 / 3 \cdot 5)=0 \cdot 17$.

The second step involved normalizing the base shear from CQC analysis, which had been modified to account for the $R$ and $U$ factors (according to step 1), to the base shear from the static code analysis. The base shear from the static code analysis was $7.61 \times 10^{2} \mathrm{kN}$. The dynamic results then had to be scaled such that base shear from the dynamic analysis, $V_{\mathrm{dyn}}$, equals $V$. The dynamic responses of interest, shear and moment, were therefore multiplied by a factor of $V / V_{\mathrm{dyn}}$. This normalization led to identical base shears from the static and dynamic analyses without including the effects of accidental eccentricity.

\section{RESULTS OF ANALYSIS}

This investigation included three equivalent static lateral force analyses and one dynamic analysis for each building case. The first of the static analyses conducted utilized CR as the centre of reference, the second utilized the CT as the centre of reference, and the third utilized SCT as the centre of reference. As previously mentioned, the latter two analyses revealed essentially identical locations for the reference centres.

For each wall, the static analysis results were computed for the design eccentricity values given by equations (2a) and (2b) for that which led to the larger design force for each building case. For the stiff wall, shear and bending moment were calculated based on equation (2b), $e_{d}=0 \cdot 5 e_{s}-0 \cdot 1 b$, as this expression gave the maximum effects. Conversely, for the flexible wall, the forces shown were calculated based on equation (2a), $e_{d}=1.5 e_{s}+0.1 b$, as this expression gave the maximum effects for this element. Floor displacements were calculated as well although results are not presented for brevity.

\section{EVALUATION OF STATIC CODE PROCEDURE}

\section{Comparison of static and dynamic responses}

Having calculated member forces for each building case, shear and moment envelopes are plotted in Figures 4-7. For stiff and flexible wall elements, static results according to all three previously defined reference centres are shown. Dynamic results are also presented with appropriate normalization as mentioned earlier for each building case.

Figures 4a and 6a show the shear and moment envelopes, respectively, for the stiff wall of building case 1. It is apparent that the static code provisions lead to results that are conservative (by about 20 per cent) in the estimation of the design forces for the stiff wall. Similar results for the flexible wall (Figures 5a and 7a) reveal that the static code analysis provides a very close evaluation, with only a slight underestimation, of the design forces of the flexible wall. Therefore, for the torsionally stiff building case 1 , the static code analysis provided a conservative or very close estimation of the design forces of the building edge elements.

The torsionally flexible building case 3 shows a large discrepancy between the static and dynamic design forces. The static code analysis provides a very notable underestimation of the design forces for the stiff wall (about 23 per cent) and at the same time provides a significant overestimation of the design forces for the flexible wall (about 34 per cent).

Building case 2 was described as a system having significant coupling between lateral and torsional motions. This building case falls between the torsionally flexible and torsionally stiff extremes of building cases 1 and 3, respectively. Recall the near-identical modal participation factors (Table IV) and roof displacements (Figure 3) for the first two modes. The shear and moment envelopes of Figures $4 \mathrm{~b}$ and $6 \mathrm{~b}$ 
Case 1

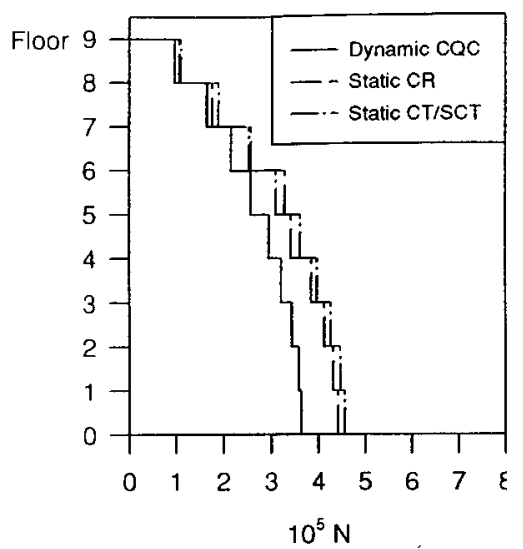

(a)
Case 2

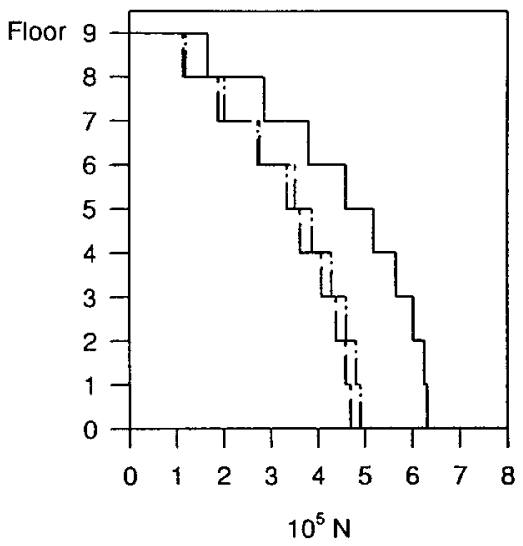

(b)
Case 3

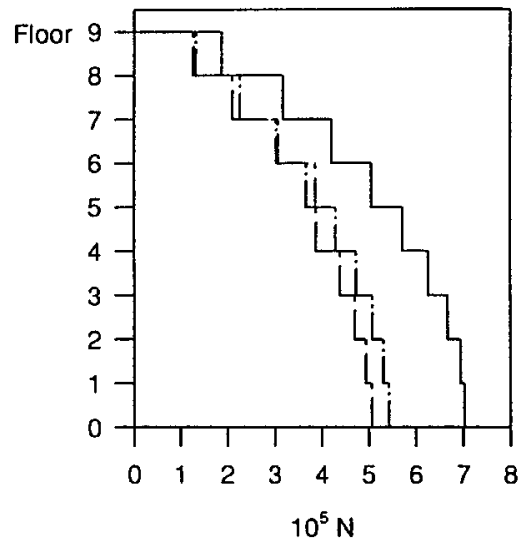

(c)

Figure 4. Shear envelopes for stiff wall, cases 1-3

Case 1

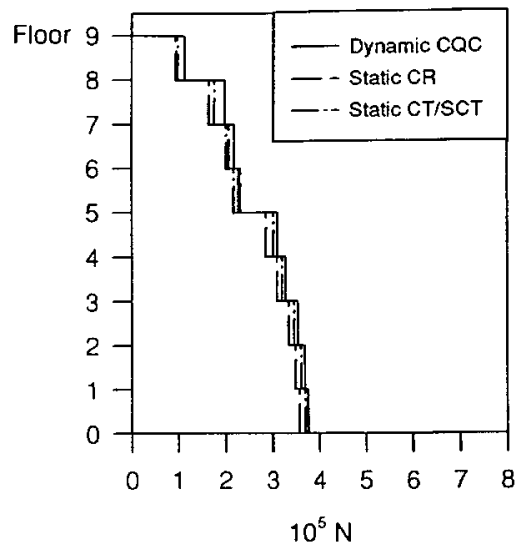

(a)
Case 2

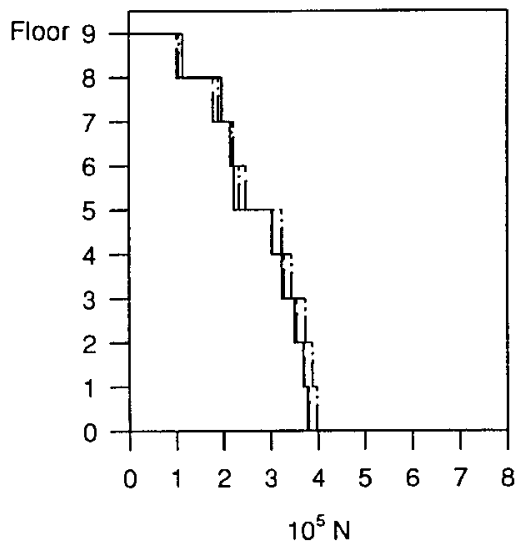

(b)
Case 3

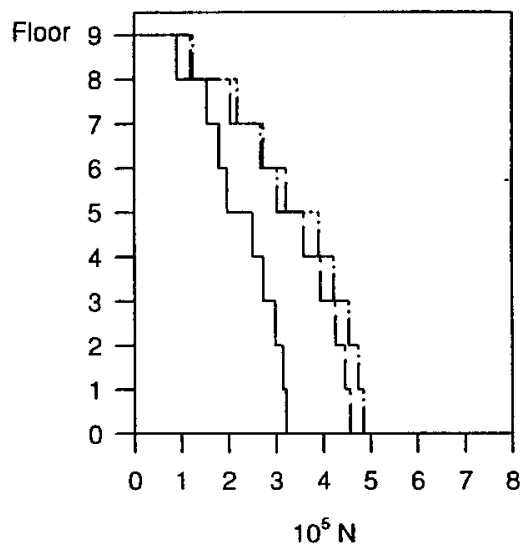

(c)

Figure 5. Shear envelopes for flexible wall, cases 1-3

show the static code significantly underestimates (about 23 per cent) the design forces for the stiff wall as was shown for case 3 . The static results compare very well for the flexible wall, shown in Figures $5 \mathrm{~b}$ and $7 \mathrm{~b}$, as was evident in case 1 .

Previously, it has been generally believed that for torsionally flexible buildings, the static code procedure may lead to underestimation of design forces for stiff edge elements. This is indeed quite the case as evident from the above discussion and can be clearly shown by the torsionally flexible building case 3 (Figures $4 \mathrm{c}$ and $6 \mathrm{c})$.

\section{Comparison of static responses using various reference centres}

Figures 4-7 also show that the differences between results from analyses based on the CRs and CTs/SCTs were very small. For the shear envelopes, a slight variance was encountered between the fifth and seventh 
Case 1

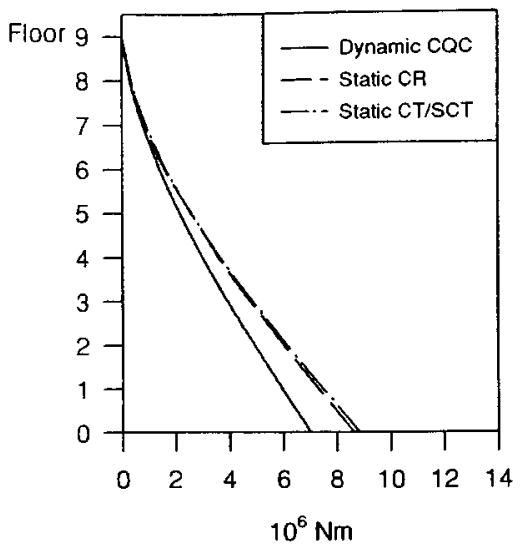

(a)
Case 2

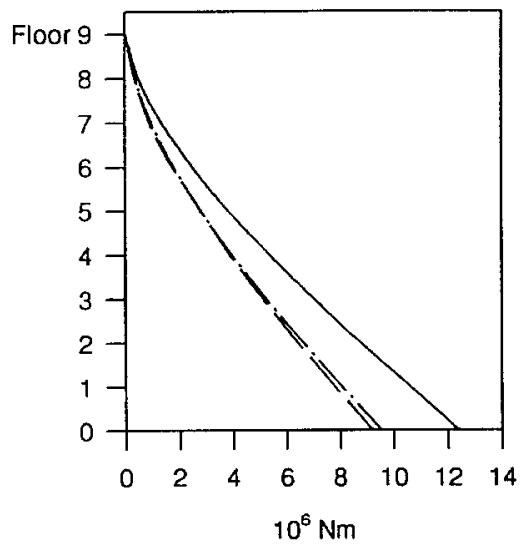

(b)

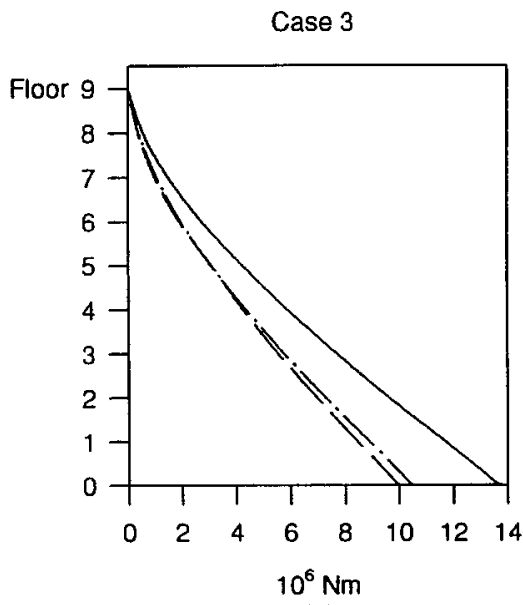

(c)

Figure 6. Moment envelopes for stiff wall, cases 1-3

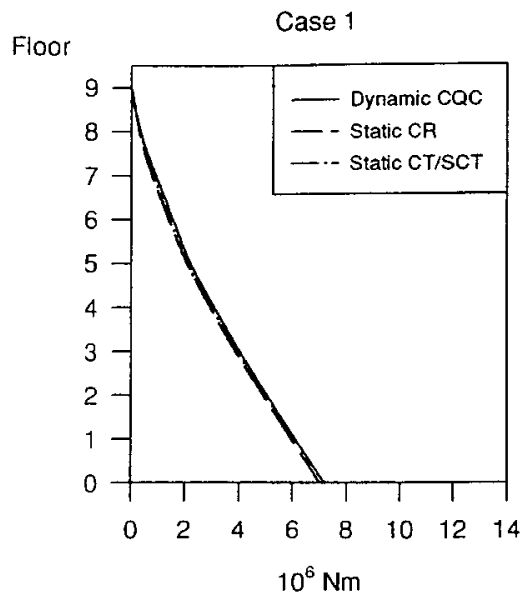

(a)

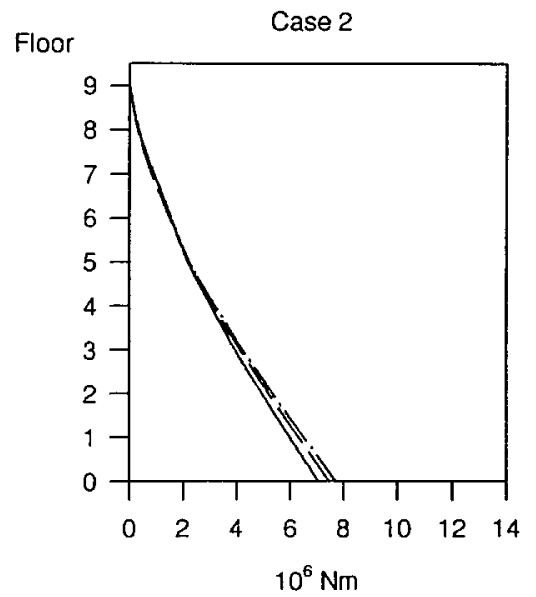

(b)

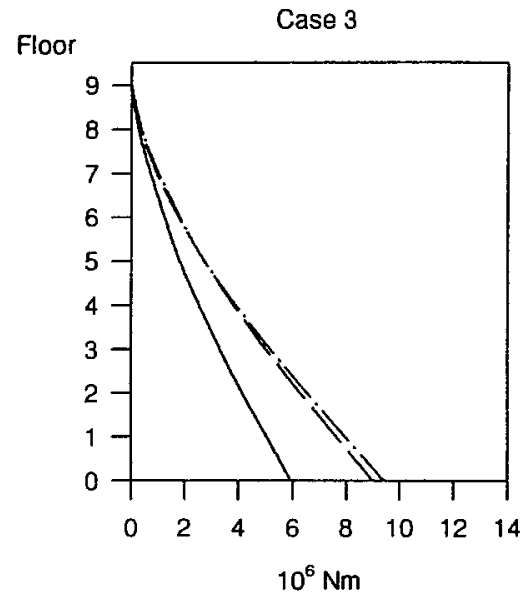

(c)

Figure 7. Moment envelopes for flexible wall, cases 1-3

floors, where the shear forces from CR become slightly larger than those from CT. At all floor levels, the shears from CR were slightly smaller than from CT. This variation was due to the dramatic change in the location of the CR at the fifth floor level (Figure 2). For case 1, the CRs on the fourth, fifth, and sixth floors had values of $-8 \cdot 14,8 \cdot 37$ and $-10 \cdot 39 \mathrm{~m}$, respectively (Table III). This represented a change in the location of the CR of $16.5 \mathrm{~m}$ between the fourth floor and the fifth floor, and $18.8 \mathrm{~m}$ between the fifth floor and the sixth floor. The trend displayed by the bending moments was similar to that in the shear force, except that the differences were even smaller.

Despite the vast difference in the locations of the reference centres, this large difference was not evident in the member forces. Even though the locations of the CRs were clearly not along a straight line, the results showed little difference from those using the nearly straight line distribution of the CTs/SCTs. 
It is generally believed ${ }^{17-19}$ (although not explicitly stated in NBCC-95) that the equivalent static lateral force analysis specified in seismic codes is applicable only when the centres of mass and the centres of reference lie approximately on vertical lines. Otherwise, a dynamic analysis must be carried out. However, the results for the selected building showed that even though the CRs do not lie on a vertical line (Figure 2), there was little difference between results from the dynamic and static analysis. This was particularly so for the flexible wall of building cases 1 and 2. Therefore, the requirement that the reference centres lie on a vertical line may be overly restrictive and should be further examined.

The above results also show that it may be an advantage to implement a simplified analysis procedure based on CR, as presented by Goel and Chopra ${ }^{10}$ which eliminates the need to explicitly calculate the reference centre; this procedure is already recommended in NBCC-95 (User's Guide: Part 4 [NBC-95 4.1.9.1.(28) $]^{14}$ ) as one of the methods from several available for implementation of the code static procedure for asymmetric-plan buildings. The analysis using CT/SCT would be quite cumbersome, as their locations would have to be calculated explicitly. Furthermore, as demonstrated in this section, the member forces obtained with CTs/SCTs as the reference center are not too different from those obtained using CRs as the reference centres for each of the three building cases.

\section{CONCLUSIONS AND RECOMMENDATIONS}

The objectives of this study were to evaluate which reference centre when used in conjunction with the NBCC-95 static code procedure, yielded results in good agreement with results from the dynamic analysis. For this purpose, responses of three building systems: a torsionally stiff, a torsionally flexible, and a medium between the two extremes were investigated. The study led to the following conclusions and recommendations:

(a) Even though location of the CRs and CTs/SCTs were significantly different, the equivalent static lateral load analysis procedure of NBCC-95 utilizing these reference centres led to very similar member design forces.

(b) The generally believed requirement that the reference centres lie on a vertical line for the code static procedure to be applicable may be overly restrictive and needs to be further examined.

(c) The static code design force results were very close (flexible wall) or slightly conservative (stiff wall) when compared to the results obtained from the dynamic response spectrum analysis for the torsionally stiff building (case 1). However, the static code procedures significantly overestimated the flexible wall design forces, when compared to the dynamic analysis results, of the torsionally flexible building (case 3 ). In addition, the static code procedures significantly underestimated the stiff wall design forces, when compared to the dynamic analysis results, of the torsionally flexible buildings (cases 2 and 3).

\section{REFERENCES}

1. International Association of Earthquake Engineering, Earthquake Resistant Regulations, A World List, Tokyo, Japan, 1992.

2. National Building Code of Canada 1995, National Research Council of Canada, Ottawa, 1995.

3. A. K. Chopra, Dynamics of Structures: Theory and Applications to Earthquake Engineering, Prentice Hall, Upper Saddle River, NJ, 1995.

4. R. A. Poole, 'Analysis for torsion employing provisions of NZRS 4203: 1974', Bull. New Zealand Soc. Earthquake Engng. 10, 219-225 (1977).

5. J. L. Humar, 'Design for seismic torsional forces', Canadian J. Civil Engng. 12, 150-163 (1984).

6. V. W. T. Cheung and W. K. Tso, 'Eccentricity in irregular multistory buildings', Canadian J. Civil Engng. 13, 46-52 (1986).

7. R. Hejal and A. K. Chopra, 'Earthquake response of torsionally-coupled buildings', Report No. UCB/EERC-87/20, University of California, Berkeley, CA, 1987.

8. W. Jiang, G. L. Hutchinson and A. M. Chandler, 'Definitions of static eccentricity for design of asymmetric shear buildings', Engng. Struct. 15, 167-178 (1993).

9. R. Riddell and J. Vasquez, 'Existence of centres of resistance and torsional uncoupling of earthquake response of buildings', Proc. 8th World Conf. on Earthquake Engineering, Vol. 4, 1984, pp. 187-194. 
10. R. K. Goel and A. K. Chopra 'Seismic code analysis of buildings without locating centers of rigidity', J. Struct. Engng. ASCE, 119, 3039-3055 (1993).

11. W. K. Tso, 'Static eccentricity concept for torsional moment estimation', J. Struct. Engng, ASCE, 116, 1199-1212 (1990).

12. A. P. Harasimowicz, 'Seismic code analysis of multi-storey asymmetric buildings', Master's Thesis, Syracuse University, Syracuse, NY, May, 1997.

13. R. K. Goel and A. K. Chopra, 'Evaluation of code formulas for fundamental period of buildings', CD-ROM Proc. 11th World Conf. on Earthquake Engineering, Paper No. 1127, Acapulco, Mexico, June, 1996.

14. User's Guide - NBC 1995 Structural Commentaries (Part 4), National Research Council of Canada, Ottawa, 1995.

15. P. A. Hidalgo, A. Arias and E. F. Cruz, 'A comparison of analysis provisions in seismic codes', Proc. 10th World Conf. on Earthquake Engng. 10, 5741-5746 (1992).

16. J. C. De La Llera and A. K. Chopra, 'Accidental and natural torsion in earthquake response and design of buildings', Report No. $U C B / E E R C-94 / 07$, Earthquake Engineering Research Center, University of California, Berkeley, California, June, 1994.

17. W. K. Tso and V. Meng, 'Torsional provisions in building codes', Canadian J. Civil Engng. 9, 38-46 (1982).

18. W. K. Tso, 'A proposal to improve the static torsional provisions for the national building code of Canada', Canadian J. Civil Engng. 10, 561-565 (1983).

19. K. M. Dempsy and W. K. Tso, 'An alternative path to seismic torsional provisions', Soil Dyn. Earthquake Engng. 1, 3-10 (1982). 